\title{
EXPERIMENTAL RESEARCH OF SUPERSONIC FLOW AROUND SIMULATING ROCKET-RAMJET
}

\author{
Eugene A. Maslov ${ }^{\mathrm{a}}$, Vladimir V. Klochikhin ${ }^{\mathrm{b}}$, Irina K. Zharova ${ }^{\mathrm{b}}$ \\ ${ }^{a}$ National Research Tomsk Polytechnic University, 634050 Tomsk, Russia \\ bational Research Tomsk State University, 634050 Tomsk, Russia
}

\begin{abstract}
The results of experimental researches of the structure and of the basic parameters of the air when flow around flat and axisymmetric models of rocket-ramjet engine are presented.
\end{abstract}

\section{INTRODUCTION}

Interest in rocket-ramjet engines, which combine the advantages of solid-fuel and jet engines [1], is increasing in recent years. The geometrical characteristics of the flow channel changes due to burnout of the solid charge in the process of the operation of the rocket-ramjet engine. Law burning rate of solid fuel in a flow of air is one of the main factors which influence the intra-ballistics characteristics of a rocket-ramjet engine. In this connection, the definition the fields of temperature, pressure, and rate of blowing flow in the flow channel of the engine is an important stage in the designing of rocketramjet engines. Mathematical modeling of dynamics and heat transfer in the flow channel of the rocket-ramjet engine allows you to get information about the structure of the flow, about the distribution of gas-dynamic parameters along the channel taking into account changes of its geometric characteristics due to burnout of solid fuel. It is expedient performing of comparative analysis of the numerical results and the experimental data, obtained in models of rocket-ramjet engine, for assess the adequacy of the developed mathematical models.

The results of an experimental research of the structure and the basic parameters of the air flow in the flow channel of a flat and an axisymmetric models of rocket-ramjet engine are presented in this paper.

\section{Technique of experimental research}

Experiments for a flat model of engine (Fig. 1) and an axisymmetric model of engine (Fig. 2) for the measurement of a temperature and a pressure, and for air flow visualization were performed in the range of Mach numbers $\mathrm{M}=(1 \div 7)$ and in the range of stagnation temperatures of free-stream air flow $T_{0}=(20 \div 500){ }^{\circ} \mathrm{C}$.

The experiments were performed on a model aerodynamic stand [2], which allows you to explore the actual processes in the conditions of work of rocket-ramjet engine in the open air at atmospheric pressure. The main function of the aerodynamic stand is create a supersonic impulse gas flow for perform aerodynamic and aero-physics research. Preheating a working gas to $500{ }^{\circ} \mathrm{C}$ was realised

a Corresponding author: maslov_eugene@mail.ru 
with use of Cowper-type heater, consisting of a power pipeline and of set of heat-retaining plates. Axisymmetric steel profiled nozzles by diameter exit section of $100 \mathrm{~mm}$ (Fig. 3) were used to create supersonic flow on the aerodynamic stand.
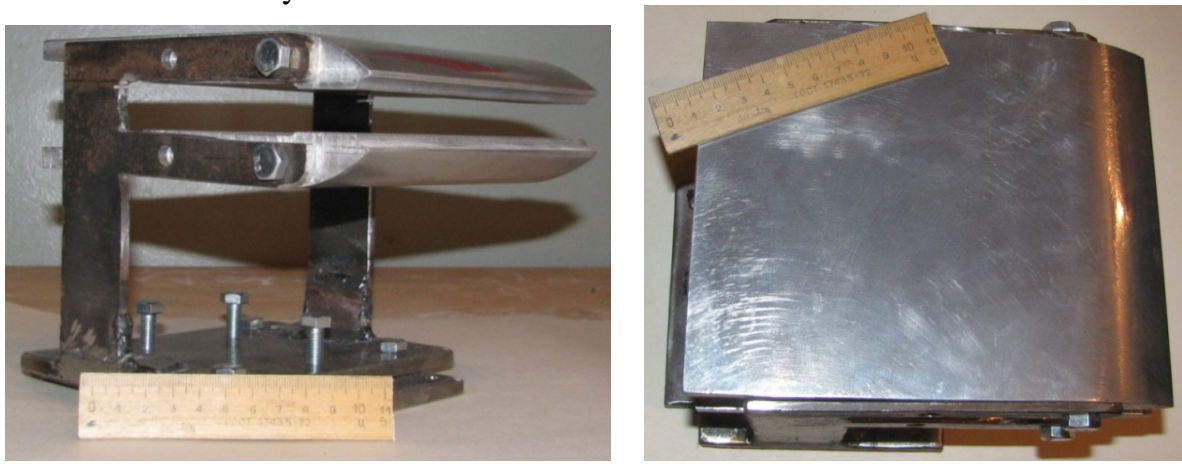

Figure 1. Photos of flat model of rocket-ramjet engine.

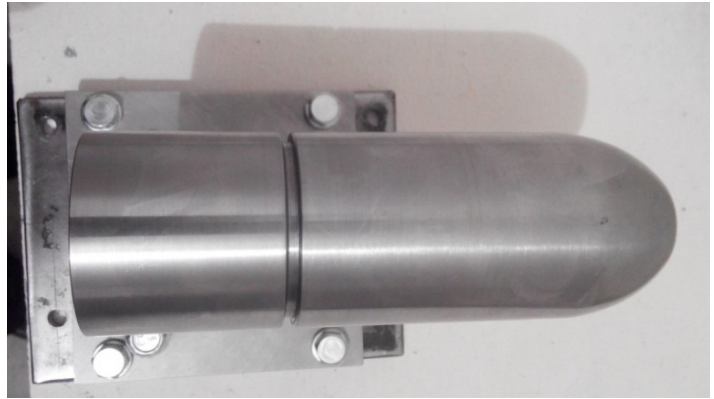

a)

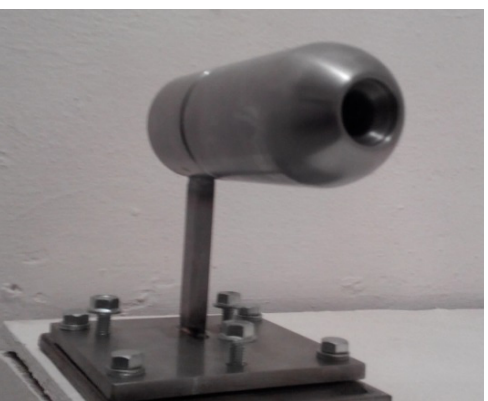

b)

Figure 2. Photo of axisymmetric model of rocket-ramjet engine. in the assembled state (a) and at the tripod (b).

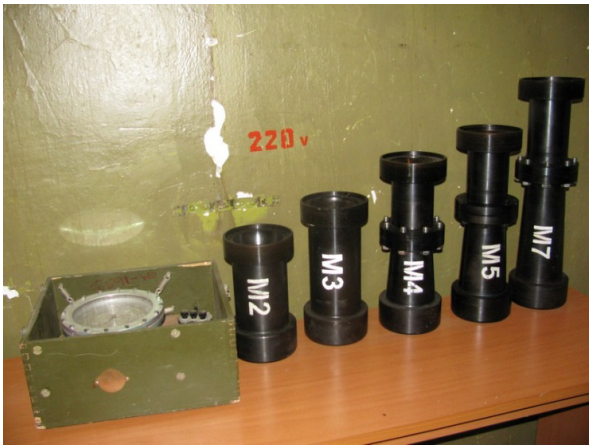

Figure 3. The supersonic nozzles.

Parameters of free-stream air flow, such as rate, static pressure, static temperature, density and Mach number are determined by values of the parameters of air in the prechamber (braking parameters) $p_{f}, T_{f}, \rho_{f}$ and of the expansion nozzle of aerodynamic stand. The pressure in the prechamber during experiments were measured by sensor ДМ 5007А - ДИ У2. Combined receiver of pressure, capable of measuring dynamic and static pressure contemporaneously, was installed in the flow channel of the rocket-ramjet engine for determine the Mach number. Mach number can be determined using gas dynamic functions by the formula [3]: 


$$
\pi(\mathrm{M})=\frac{p}{p_{0}}=\left(1+\frac{k-1}{2} \mathrm{M}^{2}\right)^{\frac{k}{1-k}},
$$

where $p, p_{0}$ are static and dynamic pressure in the flow, respectively; $k$ is the adiabatic index of gas.

Stagnation temperature $T_{0}$ in the flow channel of models under a heated flow air was measured with a chromel-copel thermocouple junction with diameter of $0.2 \mathrm{~mm}$. A thermocouple was placed on the axis of symmetry of the flow channel near the initial section.

\section{The results of experimental study}

Typical results of measurements of pressure in the prechamber (a), dynamic (b) and static pressure (c), and the stagnation temperature (d) in the flow channel of an axially symmetric model of rocket-ramjet engine for Mach number $M_{\text {in }}=5$ (M5 nozzle) shown in Fig. 4.

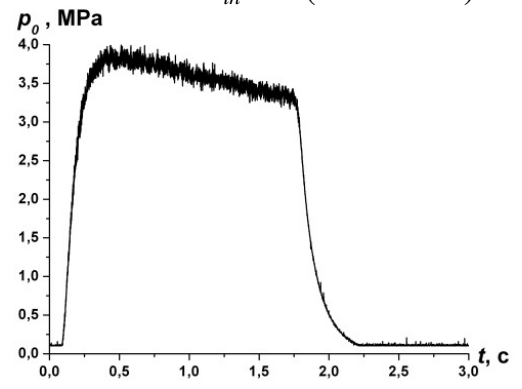

a)

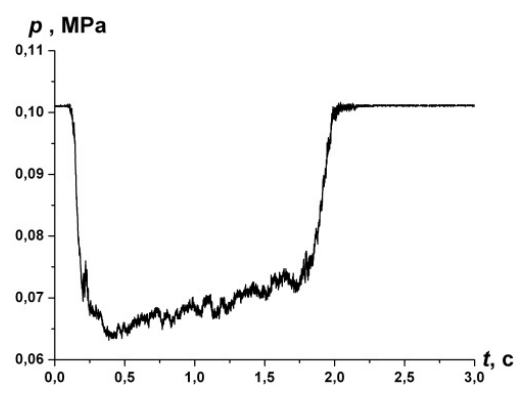

c)

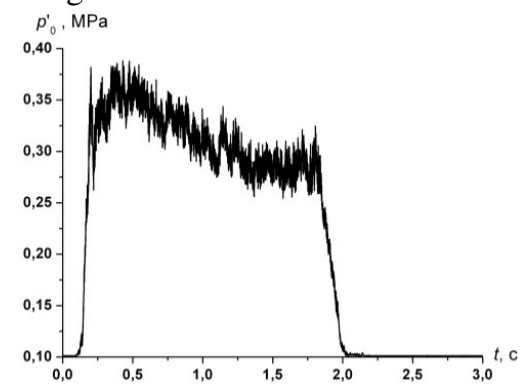

b)

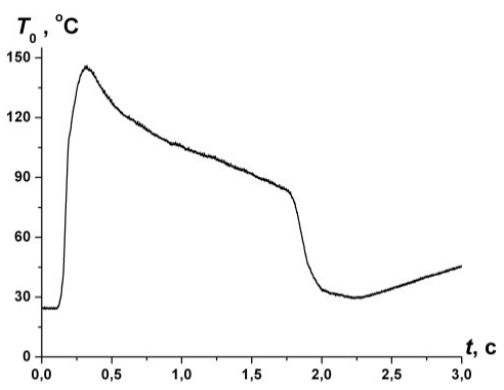

d)

Figure 4. Measurement results: The pressure in the prechamber (a), dynamic pressure (b), static pressure (c), the stagnation temperature (d) in the flow channel of axisymmetric model rocket-ramjet engine, $5 \mathrm{M}$ nozzle.

Visualizing the structure of the air flow using a high-speed video-camera was held in a series of experiments during flow around models of rocket-ramjet engines along with measurements of the basic parameters. Typical video-cadres of structure formation of the heated air flow in a flat rocketramjet model for Mach number $\mathbf{M}_{i n}=5$ are shown in Fig. 5.

Typical video-cadres of structure formation of the heated air flow in a flat rocket-ramjet model for Mach number $\mathrm{M}_{i n}=5$ are shown in Fig. 6. 


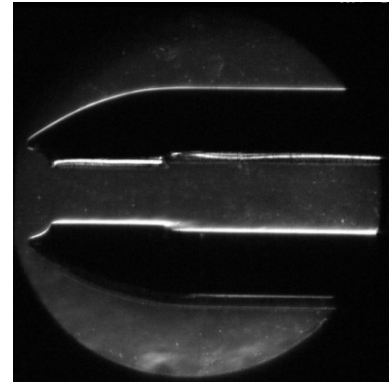

$t \sim 0.00 \mathrm{sec}$

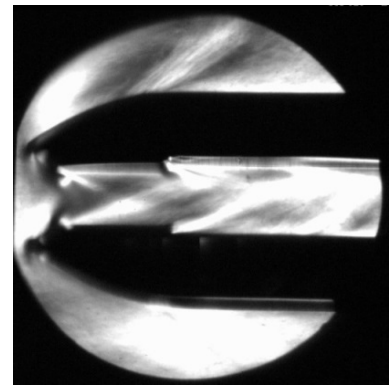

$t \sim 1.34 \mathrm{se}$

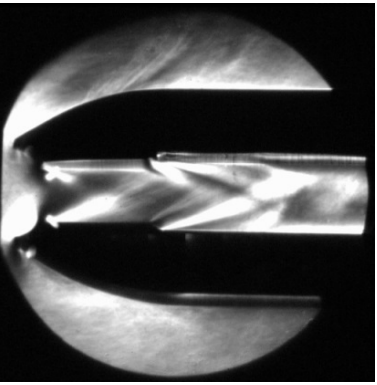

$t \sim 0.23 \mathrm{sec}$

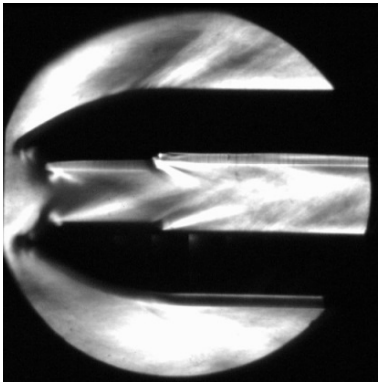

$t \sim 2.05 \mathrm{sec}$

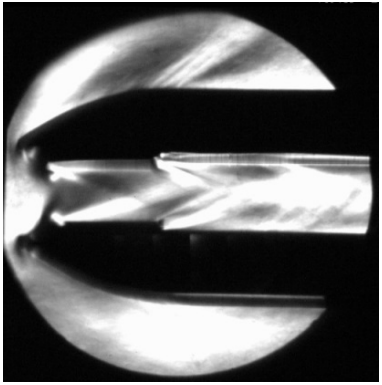

$t \sim 0.56 \mathrm{sec}$

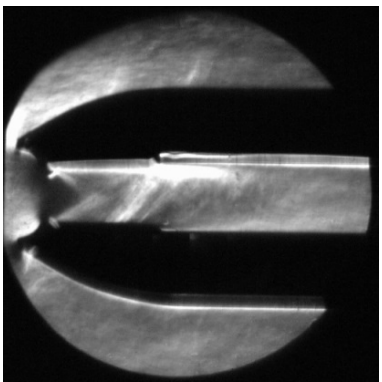

$t \sim 2.45 \mathrm{sec}$

Figure 5. Video-cadres of flow around flat model rocket-ramjet engine, $\mathrm{M}=5, T_{f}=400{ }^{\circ} \mathrm{C}$.

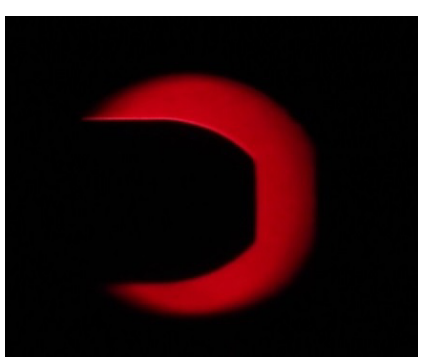

$t \sim 0.00 \mathrm{sec}$

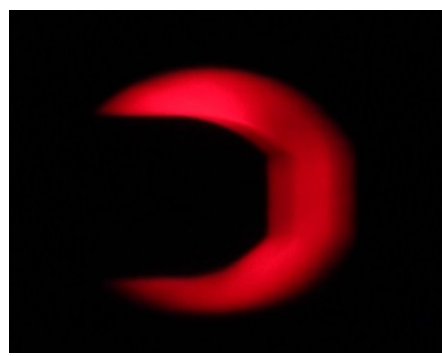

$t \sim 1.8 \mathrm{se}$

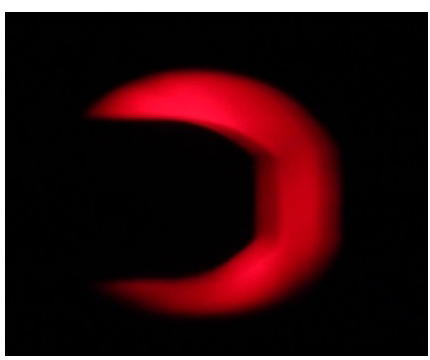

$t \sim 0.3 \mathrm{sec}$

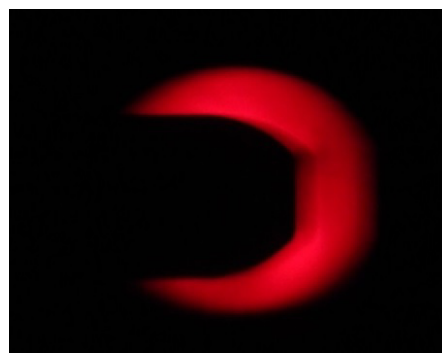

$t \sim 2.4 \mathrm{sec}$

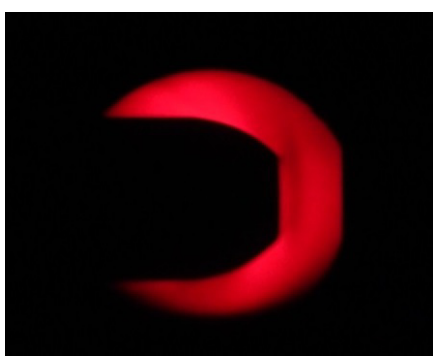

$t \sim 0.9 \mathrm{sec}$

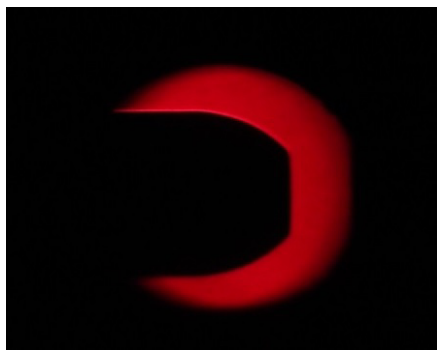

$t \sim 4.5 \mathrm{sec}$

Figure 6. Video-cadres of flow around axially symmetric model rocket-ramjet engine, $\mathrm{M}=5, T_{f}=400{ }^{\circ} \mathrm{C}$. 


\section{Conclusion}

Analysis of visualized flow structure showed that the flow with a set of oblique shocks develops in the flow channel of rocket-ramjet engine models for regimes of flow which are realized.

Obtained for models of rocket-ramjet engine experimental data on the structure and basic parameters of the air flow in the flow channel are objective information for mathematical modeling of intrachamber processes.

Funding was provided by Tomsk State University Competitiveness Improvement Program (Project № 8.2.46.2015).

\section{References}

1. B.V. Orlov, G.Yu. Mazing, A.L. Reidel, at al., Basics of designing rocket-ramjet engines for unmanned aerial vehicles, (Moscow, Mashinostroenie, 1967)

2. V.I. Zvegintsev, Gaz-dynamic installations of short-time acting, 1, Installations for scientific research (Novosibirsk, Parallel, 2014)

3. Yu.D. Irov, E.V. Keil, B.N. Maslov, at al., Gas-dynamic functions, (Moscow, Mashinostroenie, 1965) 